\title{
Simultaneous Determination of Venlafaxine and Its Main Active Metabolite $O$-Desmethyl Venlafaxine in Rat Plasma by LC-MS/MS
}

\author{
Gaurang R. ShaH, ${ }^{*}$ Bharat T. ThaKer, ${ }^{*}$ Kiran R. Surati, ${ }^{* * \dagger}$ and Minu H. Parabia*** \\ *Department of Chemistry, Veer Narmad South Gujarat University, Udhna-Magdalla Road, \\ Surat-395 007, Gujarat, India \\ **Department of Chemistry, Sardar Patel University, Vallabh Vidyanagar-388 120, Gujarat, India \\ ***Department of BioSciences, Veer Narmad South Gujarat University, Udhna-Magdalla Road, \\ Surat-395 007, Gujarat, India
}

\begin{abstract}
A simple, sensitive and selective liquid chromatography tandem mass spectrometry (LC-MS/MS) method was developed and validated for the analysis of venlafaxine (VX) and its major active metabolite $O$-desmethyl venlafaxine (ODV) in rat plasma using carbamazepine as an internal standard (IS). The analytes from the biological matrix were extracted by liquid-liquid extraction using tert-butyl methyl ether (TBME). The HPLC separation of the analytes was performed on a water symmetry $\mathrm{C} 18(150 \times 4.6 \mathrm{~mm}$ i.d., $5 \mu \mathrm{m})$ column, using a $10 \mathrm{mM}$ ammonium formate:methanol $(20: 80 \mathrm{v} / \mathrm{v})$ as mobile phase. The calibration curve concentration range was 10.10 to $8000.00 \mathrm{ng} / \mathrm{mL}$ for VX and ODV with coefficient of determination above 0.9970. The lower limit of quantification (LLOQ) of VX and ODV were 3.35 and $3.86 \mathrm{ng} / \mathrm{mL}$, respectively. The intra- and inter-day coefficients of variation were within $15 \%$.
\end{abstract}

(Received July 11, 2008; Accepted May 25, 2009; Published October 10, 2009)

\section{Introduction}

Venlafaxine (VX) is a phenethylamine bicyclic drug which is widely used in the treatment of depression. VX (Fig. 1) is a new antidepressant with a novel chemical structure that does not resemble those of any currently used antidepressants.

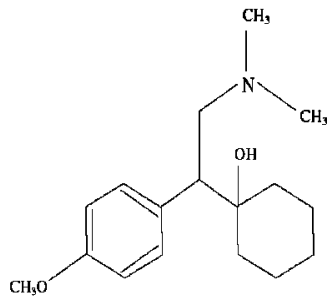

(a)

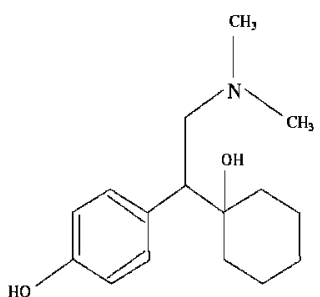

(b)<smiles>NC(=O)N1c2ccccc2C=Cc2ccccc21</smiles>

(c)

Fig. 1 Structures of (a) VX, (b) ODV and (c) carbamazepine.
Venlafaxine is not a tricylic anti-depressant or a monoamine oxidase inhibitor (MAOI) ${ }^{1}$ which inhibits the reuptake of serotonin and noradrenaline. ${ }^{2,3}$ The main advantage of this new drug compared to other classical antidepressants is that it has very few side effects, that can lead to major intoxications. ${ }^{4,5}$ In humans, VX is well absorbed and under goes metabolism in the liver. Its major metabolite, $O$-desmethyl venlafaxine (ODV) has an antidepressant activity profile similar to that of the parent drug. There are several published methods for the analysis of both VX and ODV in the human biological matrix, including GC and HPLC-UV spectrometry or mass spectrometry ${ }^{6}$ and more recently LC-MS/MS. ${ }^{7-19}$ These HPLC techniques require either liquid-liquid extraction or a solid phase extraction before the detection of drugs. Liquid-liquid extraction requires very large volumes of solvents and solid phase extraction requires various steps like buffering and solvent evaporation before being injected to HPLC and also requires longer analysis time. Hence, very little work has been conducted to determine the $\mathrm{VX}$ and its metabolite ODV simultaneously using rat plasma by LC-MS/MS.

In this communication, we describe the development of rapid, selective and sensitive LC/MS/MS methods in multiple reaction monitoring (MRM) mode for the simultaneous quantification of VX and ODV in rat plasma using carbamazepine as an internal standard. The solid phase extraction procedure is very simple and also consumes small amounts of solvents or biological matrix and has a short turn-around time for the analysis.

† To whom correspondence should be addressed.

E-mail: kiransurati@yahoo.co.in 
Table 1 Optimized MRM condition of VX, ODX and IS

\begin{tabular}{|c|c|c|c|c|c|c|c|}
\hline Analyte & Parent ion & Product ion & $\begin{array}{c}\text { Declustering } \\
\text { potential/V }\end{array}$ & $\begin{array}{l}\text { Entrance } \\
\text { potential }\end{array}$ & $\begin{array}{c}\text { Collision } \\
\text { entrance/eV }\end{array}$ & $\begin{array}{l}\text { Collision } \\
\text { entrance } \\
\text { potential }\end{array}$ & $\begin{array}{c}\text { Collision } \\
\text { exit } \\
\text { potential }\end{array}$ \\
\hline VX & $278.4[\mathrm{M}+\mathrm{H}]^{+}$ & 58.0 & 40.0 & 5.0 & 45.0 & 15.48 & 2.50 \\
\hline ODV & $264.3[\mathrm{M}+\mathrm{H}]^{+}$ & 58.0 & 40.0 & 5.0 & 45.0 & 15.13 & 2.50 \\
\hline Carbamazepine & $273.1[\mathrm{M}+\mathrm{H}]^{+}$ & 193.10 & 30.0 & 7.0 & 25.0 & 14.45 & 2.70 \\
\hline
\end{tabular}

\section{Experimental}

\section{Chemicals}

VX, ODV and carbamazepine standard drugs were of analytical reagent grade, obtained from Sigma-Aldrich. Methanol, tert-butyl methyl ether (TBME), formic acid and ammonium acetate were of HPLC grade, obtained from Spectrochem Pvt. Ltd., Mumbai, India. Ultrapure water $(18.2 \mathrm{M} \Omega / \mathrm{cm})$ was obtained from a Millipore Milli-Q water purification system. Drug free heparin based plasma of young, healthy male Sprague-Dawley (SD) rats was obtained from Aniara Co., OH (USA).

\section{Chromatographic conditions}

A Perkin-Elmer Series 200 HPLC system consisting of a flow control valve, a vacuum degasser, a pump and an autosampler was used to deliver mobile phase $10 \mathrm{mM}$ ammonium formate: methanol $(20: 80, \mathrm{v} / \mathrm{v})$ at a constant flow rate of $0.800 \mathrm{~mL} / \mathrm{min}$. The mobile phase was degassed for $20 \mathrm{~min}$ in an ultrasonic bath prior to use. The chromatographic separations were achieved on a Waters Symmetry column $(150 \times 4.6 \mathrm{~mm}$ i.d., $5 \mu \mathrm{m})$.

\section{Mass spectrometric conditions}

A Q-Trap API 2000 LC-MS/MS (Applied Biosystems/MDS Sciex, Toronto, Canada) mass spectrometer was operated with a standard electrospray ionization (ESI) source and an LC separation system. Analyst 1.3 software (Applied Biosystems) was used for the control of equipment, data acquisition and analysis. For optimization of MS parameters, $1 \mu \mathrm{g} / \mathrm{mL}$ of each analyte was prepared in methanol. Zero air was used as nebulizing gas (GS 1, $25 \mathrm{psi}$ ) and nitrogen as curtain gas (20 psi). The declustering potential (DP) was optimized while ion spray voltage, nebulizing and curtain gas conditions were used in default mode. The dwell time and mass width were set at $0.2 \mathrm{~s}$ and $\pm 10 \mathrm{amu}$ and MS scan was performed in positive mode. The product ion spectrum (MS-MS) was generated at optimized DP to identify the prominent product ions of the analysts using nitrogen as the collision gas. Collision energies (CE) optimization for the precursor to product ion transition 5 was obtained by $\mathrm{CE}$ ramping by direct infusion. The established MRM operating conditions are summarized in Table 1. A mass spectrum of VX and ODV in methanol:10 mM ammonium formate $(80: 20 \mathrm{v} / \mathrm{v})$ for parent ion was recorded in the positive ion mode with a scan range from 0 to $300 \mathrm{amu}$ and that for product ion was recorded with a scan range from 40 to $150 \mathrm{amu}$.

\section{Standard and working solution}

Standard stock solutions $1 \mathrm{mg} / \mathrm{mL}$ of VX, ODV and IS were prepared by accurately weighing $10 \mathrm{mg}$ of each analyte in a $10-\mathrm{mL}$ volumetric flask, and the volume was made up with Milli-Q water and with methanol for IS. The working stock of IS $(25 \mu \mathrm{g} / \mathrm{mL})$ was prepared in methanol:water $(90: 10 \mathrm{v} / \mathrm{v})$.
The analytical working standard of VX and ODV was prepared in methanol:water $(90: 10 \mathrm{v} / \mathrm{v})$ over a concentration range of 10 to $8000 \mathrm{ng} / \mathrm{mL}$ by serial dilution. All the stock and working standard solutions were prepared prior to start of validation and stored at $4{ }^{\circ} \mathrm{C}$. These solutions were found to be stable and were used for the method validation.

\section{Calibration standards and quality control samples}

All the calibration standards 10, 20, 60, 250, 1000, 4500, 6500 and $8000 \mathrm{ng} / \mathrm{mL}$ were prepared by spiking the respective working standard of $\mathrm{VX}$ and $\mathrm{ODV}$ in SD rat plasma. Carbamazepine (IS) $25 \mu \mathrm{L}$ was added to the plasma samples $(100 \mu \mathrm{L})$ before extraction. Quality control (QC) samples at three different concentration levels 30.60, 1020.00, $6000.00 \mathrm{ng} / \mathrm{mL}$ as low, medium and high, respectively, were prepared in five replicates each day and were used to assess the accuracy and precision of the assay method. The calibration standards and quality control samples were prepared fresh on each day of validation.

\section{Sample preparation}

Sample preparation involved a simple liquid-liquid extraction with TBME. The extraction solvent $(1 \mathrm{~mL})$ was added to $100 \mu \mathrm{L}$ aliquots of blank/spiked plasma and vortex mixed on Vibramax for $20 \mathrm{~min}$. Each sample was centrifuged at $12000 \mathrm{rpm}$ for $10 \mathrm{~min}$ at $40^{\circ} \mathrm{C}$ and the upper organic layer was transferred to another set of pre-labelled microfuge tubes and was evaporated to dryness in an $\mathrm{LV}$ evaporator at $400^{\circ} \mathrm{C}$. The dry samples were reconstituted in $150 \mu \mathrm{L}$ reconstituting solution (mobile phase). The samples $(20 \mu \mathrm{L})$ were injected onto the LC-MS/MS system.

\section{Method validation}

The method was validated in terms of linearity, specificity and selectivity, lower limit of detection (LOD) and lower limit of quantification (LLOQ), recovery, accuracy, precision, and stability. ${ }^{20}$ The accuracy and precision determined were carried out in five replicates at low, medium and high concentration levels.

\section{Linearity}

Linearity of calibration standards was assessed by subjecting the spiked concentrations and the respective peak responses to least-square linear regression analysis with and without intercepts, and to a weighted least square regression $(1 / x$ or $\left.1 / x^{2}\right)$. A proper calibration model was chosen after examination of residuals and coefficients of correlation in each case. ${ }^{21}$

\section{Specificity and selectivity}

Interferences in biological sample arise from a number of endogenous sources (analyte metabolite, degradation products and chemicals normally occurring in biological fluids) and exogenous sources (impurities in reagents and dirty lab-ware). In case producing a response for only a single analyte, ${ }^{22}$ the 
method is considered to be specific and selective. Six individual blank rat plasma samples from different sources were analyzed to ensure no endogenous interference with mass transitions chosen for VX, its metabolites ODV and IS. As a check of the selectivity of the method between the analytes, individual standard solutions at their upper limit of quantification (ULOQ) were separately injected and analyzed. An ULOQ solution of VX should not produce peaks $>20 \%$ of LLOQ of its other metabolites. The same was done for ODV to establish selectivity.

\section{$L O D$ and $L L O Q$}

The LOD for VX and ODV were defined as the drug concentration in the plasma after the sample preparation method that corresponds to three times the baseline noise $(S / N \geq 3)$. The LLOQ was defined as the concentration of the sample that can be quantified with $<20 \%$ deviation $(S / N \geq 10) .{ }^{23}$

\section{Recovery}

Recovery was determined by comparing the responses of processed quality control samples (extracted samples) with analytical responses of pure standard solution samples (un-extracted samples). These experiments were performed at three concentration levels of low, medium and high. ${ }^{24}$

\section{Accuracy and precision}

For the validation of assays, QC samples were prepared with three concentration levels of low, medium and high. Five replicates of each QC sample were analyzed together with a set of calibration standards. The accuracy of each sample preparation was determined by injection of calibration samples and three QC samples in five replicates. The accuracy was expressed as $\%$ bias. $^{25}$ The precision was expressed as the percentage coefficient of variance $(\% \mathrm{CV})$ or relative standard deviation (RSD) of replicate measurements. ${ }^{26}$

\section{Results and Discussion}

\section{Linearity and calibration standards}

The peak area ratios of VX and ODV to internal standard carbamazepine were linear over a concentration range of 10.10 to $8000.00 \mathrm{ng} / \mathrm{mL}$. The calibration curve was achieved by a linear equation of $y=m x+c$ and a $1 / x^{2}$ weighting factor for both analytes with minimum residuals and a regression coefficient $>0.9980$.

\section{Specificity and selectivity}

Chromatograms of six batches of control drug free plasma contained no co-eluting peak $>20 \%$ of analytes area at LLOQ level and no co-eluting peaks $>5 \%$ of the area of internal standard. There was no cross interference between analytes after subjecting individual analytes. Representative chromatograms of extracted blank plasma, VX and ODV are shown in Fig. 2. The retention times of both analytes and IS showed less variability, with a relative standard deviation (RSD) well within the acceptance limit of $5 \% .{ }^{27,28}$

\section{$L O D$ and $L L O Q$}

The LOD demonstrated that both analytes VX and ODV gave an $S / N$ ratio $\geq 3$ of 3.35 and $3.86 \mathrm{ng} / \mathrm{mL}$, respectively. The lowest concentration in the standard curve (LLOQ) can be measured with acceptable accuracy and precision for both $\mathrm{VX}$ and ODV from rat plasma. LLOQ was established as $10.10 \mathrm{ng} / \mathrm{mL}$.
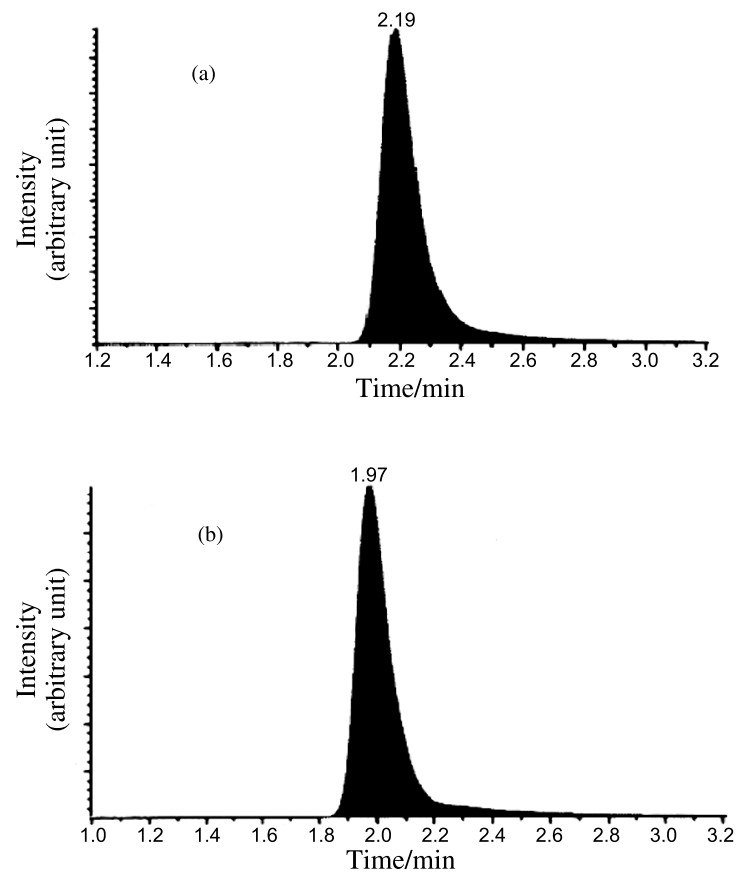

Fig. 2 Representative chromatograms of: (a) VX Q1 278.4 Q3 58.0, $\mathrm{RT}=2.18 \mathrm{~min}$, (b) ODV Q1 264.3 Q3 58.0, RT = $1.97 \mathrm{~min}$.

Table 2 Absolute recoveries of VX and ODV from rat plasma

\begin{tabular}{ccc}
\hline \multirow{2}{*}{$\begin{array}{c}\text { Concentration/ } \\
\text { ng mL }\end{array}$} & \multicolumn{2}{c}{ Absolute recovery, \% (mean $\pm \mathrm{SD}, n=5)$} \\
\cline { 2 - 3 } & $\mathrm{VX}$ & $\mathrm{ODV}$ \\
\hline 30.36 & $71.91 \pm 3.33$ & $76.79 \pm 3.11$ \\
1020.00 & $81.45 \pm 5.99$ & $72.85 \pm 2.68$ \\
6000.00 & $86.79 \pm 2.25$ & $85.83 \pm 2.94$ \\
\hline
\end{tabular}

\section{Recovery}

The extraction recovery was determined for three concentrations $30.36,1020.00,6000.00 \mathrm{ng} / \mathrm{mL}$ as described 2.7.4. The average absolute recoveries for $\mathrm{VX}$ and ODV at three different concentration $(n=5)$ are shown in Table 2.

\section{Accuracy and precision}

The intra-day and inter-day accuracy and precision were calculated at four different concentration levels of low, medium, high and LLOQ quality control samples for all analytes on 5 days. The results showed that the analytical method is accurate, as the bias is within the acceptance limit of $\pm 20 \%$ of the theoretical value at LLOQ and $\pm 15 \%$ at all other concentration levels (Table 3). The precision around the mean value was within the acceptance limit of $\pm 15 \%$ for all the concentrations. Stability studies found that VX and ODV were stable in the stock and working solutions, in rat plasma for over $24 \mathrm{~h}$ at ambient temperature. Furthermore, analytes and IS were stable at least for three months in the stock solution at $4^{\circ} \mathrm{C}$. The three freeze-thaw cycles were done by thawing samples at high, medium and LLOQ concentration and allowing them to freeze again for at least $12-24 \mathrm{~h}$. The cycle was repeated twice. The samples were processed at the end of third cycle and the results were compared with those of a freshly prepared sample. The deviations observed after first, second and third freeze-thaw cycles were within $\pm 15 \%$. 
Table 3 Accuracy (\% basis) and precision (\% RSD) of analytes

\begin{tabular}{|c|c|c|c|c|c|}
\hline \multirow{2}{*}{ Analyte } & \multirow{2}{*}{$\begin{array}{l}\text { Concentration/ } \\
\text { ng mL } \mathrm{mL}^{-1}\end{array}$} & \multicolumn{2}{|c|}{ Accuracy, $\%$ (basis) } & \multicolumn{2}{|c|}{ Precision, $\%$ (RSD) } \\
\hline & & Inter-day & Intra-day & Inter-day & Intra-day \\
\hline \multirow[t]{4}{*}{ VX } & 10.10 & 1.92 & 3.42 & 10.57 & 8.52 \\
\hline & 30.36 & 5.94 & 8.27 & 3.75 & 6.60 \\
\hline & 1020.00 & 5.09 & 3.03 & 2.93 & 3.27 \\
\hline & 6000.00 & -8.00 & -12.52 & 1.23 & 1.30 \\
\hline \multirow[t]{4}{*}{ ODV } & 10.10 & 6.72 & 1.39 & 5.41 & 4.05 \\
\hline & 30.36 & -6.57 & -4.49 & 2.88 & 1.62 \\
\hline & 1020.00 & 1.19 & 2.18 & 5.65 & 4.05 \\
\hline & 6000.00 & 3.55 & 3.55 & 3.08 & 1.94 \\
\hline
\end{tabular}

\section{Conclusion}

A LC-MS-MS bioanalytical method for simultaneous determination of venlafaxine hydrochloride and its metabolite ODV was developed and validated in rat plasma. This method has significant advantages over those, previously reported, in terms of sensitivity, selectivity and shorter run time $(3.5 \mathrm{~min})$. The 233 established LLOQ of $10.10 \mathrm{ng} / \mathrm{mL}$ of VX is sufficiently low for carrying out pharmacokinetic studies to obtain realistic pharmacokinetic parameters. The extraction method gave consistent and reproducible recoveries for analytes from rat plasma, with no interference. The results of validation indicate that the method can be considered suitable for carrying out preclinical pharmacokinetic studies of VX in rat plasma.

\section{References}

1. Duvermeuil, Ther. Drug. Monit., 2003, 25, 565.

2. E. Muth, J. Haskin, J. Moyer, G. M Husbands, S. Nielson, and E. Sigg, Biochem. Pharmacol., 1986, 35, 4493.

3. M. Matoga, F. Pehourcq, K. Titier, F. Dumora, and C. Jarry, J. Chromatogr., B, 2001, 760, 213.

4. V.P. Leung, H.F. Chiu., and L.C. Lam, Pharmacopsychiatry, 1998, 31, 32.

5. B. Skop, T. Rocha, V. Morsch, R. Neis, and M. Schetinger, Biochim. Biophys. Acta, 2002, 1587, 92.

6. E. Lacassie, J. Gaulier, P. Marquet, J. Rabatel, and G. Lachatre, J. Chromatogr., B, 2000, 742, 17.

7. J. Bhatt, A. Jangid, G. Venkates, G. Subaiah, and S. Singh, J. Chromatogr., B, 2005, 829, 75 .

8. A. Castro, M. Concheiro, O. Quintela, A. Cruz, and M. López-Rivadulla, J. Pharm. Biomed. Anal., 2008, 48, 183.
9. B. Patel, N. Sharma, M. Sanyal, and P. Shrivastav, J. Pharm. Biomed. Anal., 2008, 47, 603.

10. N. Castaing, K. Titier, M. Receveur-Daurel, M. Le-Déodic, D. Le-Bars, N. Moore, and M. Molimard, J. Anal. Toxicol., 2007, 31, 334.

11. Z. Wei, X. Bing-Ren, and W. Cai-Yun, Biomed. Chromatogr., 2007, 21, 266.

12. W. Smyth, J. Leslie, S. McClean, B. Hannigan, H McKenna, B. Doherty, C. Joyce, and E. O'Kane, Rapid Commun. Mass Spectrom., 2006, 20, 1637.

13. P. Cutroneo, M. Beljean, R. Luu, and A. Siouffi, J. Pharm. Biomed. Anal., 2006, 41, 333.

14. K. Titier, N. Castaing, E. Scotto-Gomez, F. Pehourcq, N. Moore, and M. Molimard, Therap. Drug Monit., 2003, 25, 581 .

15. C. Duverneuil, G. Grandmaison, P. Mazancourt, and J. Alvarez, Therap. Drug Monit., 2003, 25, 565.

16. B. Raut, B. Kolte, A. Deo, M. Bagool, and D. Shinde, $J$. Liq. Chromatogr. Relat. Technol., 2003, 26, 1297.

17. K. Goeringer, I. McIntyre, and O. Drummer, J. Anal. Toxicol., 2003, 27, 30.

18. G. Tournel, N. Houdret, V. Hédouin, M. Deveaux, D. Gosset, and M. Lhermitte, J. Chromatogr., B, 2001, 761, 147.

19. J. Bickeboeller-Friedrich and H. Maurer, Therap. Drug Monit., 2001, 23, 61.

20. L. Labat, M. Deveaux, P. Dallet, and J. Dubost, $J$. Chromatogr., B, 2002, 773, 229.

21. P. Shah, K. Midha, W. Findlay, M. Hill, D. Hulse, J. Mcgilveray, G. Mckay, J. Miller, N. Patnaik, L. Powell, A. Tonelli, C. Viswanathan, and A. Yacobi, Pharm. Res., 2000, 17, 1551.

22. N. Nagaraja, J. Paliwal, and R. Gupta, J. Pharm. Biomed. Anal., 1999, 20, 433.

23. D. Dadgar and P. Burnett, J. Pharm. Biomed. Anal., 1995, 14, 23.

24. R. Causon, J. Chromatogr., B, 1997, 689, 175.

25. F. Bressolle, M. Bromet-pitit, and M. Audran, $J$. Chromatogr., $B, \mathbf{1 9 9 6}, 686,3$.

26. Anonymous, May 2001, Guide for Industry, Bioanalytical Method Validation, 2001, U. S. Department of Health and Human Services, Food and Drug Administration (FDA).

27. F. Bressolle, M. Bromet-Petit, and M. Audran, $J$. Chromatogr., B, 1996, 686, 3.

28. Guidance for Industry, Mass Spectrometry for Confirmation of the Identity of Animal Drug Residues, Draft Guidance, 2001, U. S. Department of Health and Human Services, Food and Drug Administration, Washington, D.C. 